\title{
Application of Membrane-Selective Electrodes for the Determination of Naftidrofuryl Oxalate in the Presence of Its Alkaline Degradant in Tablets and Plasma
}

\author{
Samah S. Abbas, Hala E. Zaazaa, Mohamed R. El-Ghobashy, \\ Yasmin M. Fayez and Soheir A. Fattah \\ Analytical Chemistry Department, Faculty of Pharmacy, Cairo University, \\ Kasr El-Aini St.,11562, Cairo, Egypt
}

Received 11 March 2012; accepted 30 June 2012

\begin{abstract}
Membrane selective electrodes were used to determine Naftidrofuryl Oxalate (NFL) in presence of its alkaline degradate (I). The membrane selective electrodes include construction of water insoluble ion-association complexes. These are NFL-tetraphenyl borate (NFL-TPB), NFL- reinikate (NFL-R). These complexes are used as electroactive materials, in poly-vinyl chloride (PVC) matrix membrane sensors, for the determination of NFL. The performance characteristics of these sensors, evaluated according to IUPAC recommendations, reveal fast, stable and linear response for NFL. The sensors are used for determination of NFL in plasma.

The suggested method was used to determine NFL in synthetic mixtures and in commercial tablets.

The obtained results were statistically compared with official HPLC method, showing no significant difference with respect to accuracy and precision.
\end{abstract}

Keywords: naftidrofuryl oxalate; PVC membranes; ion selective electrode.

\section{Introduction}

Naftidrofuryl oxalate is tetrahydro- $\alpha$-(1-naphthalenylmethyl)-2-furanpropanoic acid 2-(di-ethylamino) ethyl ester acid oxalate, as shown in Fig. 1 [1]. Several methods have been recommended for the determination of NFL; these include titrimetric method (1), HPLC (2-5), capillary zone electrophoresis (6), electrochemical method (7) and phosphorimetry (8-12). The NFL is an official drug in BP. It is desirable to develop a simple and fast procedure that could be

\footnotetext{
* Corresponding author. E-mail: mohamedrefaat73@yahoo.com
} 
applied in quality control laboratories for the selective determination of NFL in the presence of its degradate. The utility of the developed methods to determine the content of drug in its pharmaceutical dosage form is also demonstrated.

The suggested method is simple, rapid and from the economical point of view, all analytical reagents used are inexpensive, have excellent shelf life and are available in any analytical laboratory.

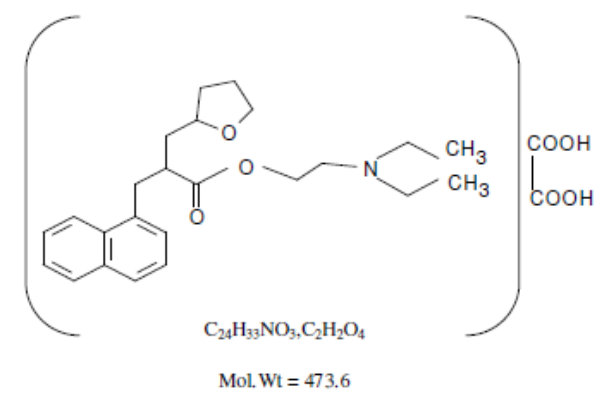

Figure 1. Chemical structure of naftidrofuryl oxalate.

\section{Experimental}

\section{Instruments}

Potentiometric measurements were made at $30 \pm 1^{\circ} \mathrm{C}$ with a Hanna (Model 211) $\mathrm{pH} / \mathrm{mV}$ meter. A double junction silver reference electrode (Model HI 5412) was used in conjunction with the drug sensor. A WPA pH combined glass electrode Model CD 740 was used for $\mathrm{pH}$ measurements. Ultrasonic, Bandelin electronic, Sonorex RK51OS, HF-Frequency 35 $\mathrm{KHz}$ (10 liter capacity), Germany.

\section{Reagents and solvents}

All reagents used throughout this work were of analytical pure grade, and solvents were of spectroscopic grade.

Methanol, water, chloroform (HPLC grade).

Tetrahydrofuran (THF) 99\% (Lab Scan).

High molecular weight (10000) polyvinyl chloride (PVC) powder, sodium tetraphenyl borate (Na TPB) and 2-nitrophenyl octyl ether (NPOE) (Aldrich).

Dibutylsebathete, sodium reineckate (R) and dioctyl phthalate (DOP); Sigma.

Polyvinyl chloride carboxylated (PVC-COOH) and B-cyclodextrin ( $\beta-\mathrm{CD})$; (Fluka chemie GmbH Germany).

Sodium hydroxide, $1 \mathrm{M}$ aqueous solution and hydrochloric acid, $1 \mathrm{M}$ aqueous solution; Prolabo.

Phosphate buffer $\mathrm{pH} 2.5,4$ and 4.5 were prepared (1).

\section{Samples}

Pure standard

NFL was kindly supplied by MINAPHARM-Egypt under license of MERK France, having a purity of $100.28 \pm 1.119$ (1). 
Pharmaceutical dosage form

Praxilene ${ }^{\circledR}$ film coated tablets (MINAPHARM-Egypt under license of MERK France) labeled to contain $200 \mathrm{mg}$ of NFL per tablet, batch number 6IE1312.

\section{Degraded sample}

Preparation of alkaline degradate of NFL

It was prepared by dissolving $25 \mathrm{mg}$ of NFL in $9 \mathrm{~mL}$ water, then $10 \mathrm{~mL}$ methanol were added followed by $4 \mathrm{~mL}$ of $1 \mathrm{~N} \mathrm{NaOH}$ and refluxing for 4 hours. The solution was neutralized, evaporated to dryness on hot plate and then the residue was dissolved in $20 \mathrm{~mL}$ methanol. The obtained solution was filtered into $25 \mathrm{~mL}$ volumetric flask and the volume was completed with methanol to have a concentration of $1 \mathrm{mg} \mathrm{mL}^{-1}$.

\section{Standard stock and working solutions}

Standard stock solution of NFL $\left(10^{-2} \mathrm{M}\right)$ in water and acetate buffer $(\mathrm{pH} \mathrm{2.5,} 4$ \& 4.5).

Standard stock solution of alkaline degradate $\left(10^{-2} \mathrm{M}\right)$ in acetate buffer $(\mathrm{pH} 2.5,4$ \& 4.5).

Working standard solution of NFL and alkaline degradate $\left(10^{-6}-10^{-3} \mathrm{M}\right)$ of each in acetate buffer ( $\mathrm{pH} 2.5,4 \& 4.5)$.

Laboratory prepared mixtures of different ratios from 10 to $90 \%$ of NFL alkaline degradate and NFL.

\section{Procedures}

Preparation of naftidrofuryl PVC membrane sensors

Preparation of NFL-TPB membrane sensor (sensor 1)

$10 \mathrm{~mL}$ of $10^{-2} \mathrm{M}$ aqueous solution of NFL were mixed with $10 \mathrm{~mL}$ of a saturated aqueous solution of sodium tetraphenyl borate. The resulting precipitate was filtered, washed with cold water, allowed to dry at room temperature and grounded to fine powder, forming the ion-pair complex. In a glass Petri dish (5 $\mathrm{cm}$ diameter), $10 \mathrm{mg}$ of the ion pair complex were mixed with $0.35 \mathrm{~mL}$ of dibutylsebathete, then $0.19 \mathrm{~g}$ of PVC were added. The mixture was dissolved in tetrahydrofuran (THF). The Petri dish was covered with a filter paper and allowed to stand overnight, thus a master membrane with $0.1 \mathrm{~mm}$ thickness was obtained. Sensor was assembled using a punched circular membrane (about 8 $\mathrm{mm})$. This was conditioned by soaking for 24 hours into $10^{-2} \mathrm{M}$ aqueous drug solution and stored in the same solution when not in use.

\section{Preparation of NFL-R membrane sensor (sensor 2)}

$10 \mathrm{~mL}$ of $10^{-2} \mathrm{M}$ aqueous solution of NFL were mixed with $10 \mathrm{~mL}$ of a saturated aqueous solution of sodium reinekete. The resulting precipitate was filtered, washed with cold water, allowed to dry at room temperature and grounded to fine powder, forming the ion-pair complex.

In a three glass Petri dishes ( $5 \mathrm{~cm}$ diameter), $10 \mathrm{mg}$ of the ion pair complex were mixed with $0.35 \mathrm{~mL}$ of dioctyl phthalate (sensor $2 \mathrm{a}$ ), dibutylsebathete (sensor 
2b) and NPOE (sensor 2c), separately, then $0.19 \mathrm{~g}$ of PVC were added to each one. The mixture was dissolved in tetrahydrofuran (THF).

The Petri dishes were covered with a filter paper and allowed to stand overnight, thus three master membranes with $0.1 \mathrm{~mm}$ thickness were obtained.

Sensors were assembled using a punched circular membrane (about $8 \mathrm{~mm}$ ). This was conditioned by soaking for 24 hours into $10^{-2} \mathrm{M}$ aqueous drug solution and stored in the same solution when not in use.

\section{Preparation of NFL- $\beta$-CD/PVC-COOH membrane sensor (sensor 3)}

In a glass Petri dish ( $5 \mathrm{~cm}$ diameter), mix $0.04 \mathrm{~g} \beta$-CD with $0.4 \mathrm{~g}$ of DOP, then $0.19 \mathrm{~g}$ of PVC-COOH were added. The mixture was dissolved in tetrahydrofuran (THF). The Petri dish was covered with a filter paper and allowed to stand overnight, thus a master membrane with $0.1 \mathrm{~mm}$ thickness was obtained.

The sensor was assembled using a punched circular membrane (about $8 \mathrm{~mm}$ ). This was conditioned by soaking for 24 hours into $10^{-2} \mathrm{M}$ aqueous drug solution and stored in the same solution when not in use.

\section{Sensor calibration}

The sensor and double junction silver reference electrode were immersed in drug solution in acetate buffer $(\mathrm{pH} 2.5,4 \& 4.5)$ in the range of $10^{-6}-10^{-2} \mathrm{M}$. They were allowed to equilibrate within $\pm 1 \mathrm{mV}$. Between measurements the membrane sensor was washed with water. The $\mathrm{mV}$-concentration profile was plotted. The regression equation for the linear part of the curve was computed and used for subsequent determination of unknown NFL concentration.

\section{Selectivity measurements}

Potentiometry selectivity coefficients (K Pot A, B) were evaluated according to IUPAC guidelines using the separate solutions method $(13,14)$ where A refers to (Drug ions) and B refers to (interfering ion).

The emf for $A$ and $B$ are measured values $\left(E_{a}\right.$ and $\left.E_{b}\right)$, respectively. Different interfering anions at a concentration of $1 \times 10^{-4} \mathrm{M}$ at a suitable $\mathrm{pH}$ were utilized and the results were obtained using the equation

$$
\log K_{A, B}^{P o t}=\frac{(E B-E A)}{S}+\left(1-\frac{Z A}{Z B}\right) \log \mathrm{aA}
$$

where $K_{A, B}^{\text {Pot }}$ is the potentiometric selectivity coefficient, $\mathrm{S}$ is slope of the calibration plot, aA is the activity of drug, and $\mathrm{ZA}$ and $\mathrm{ZB}$ are the charges on drug and interfering ion, respectively.

\section{Application of laboratory prepared mixtures}

The membrane sensors were immersed in conjunction with the double junction silver reference electrode in the different laboratory prepared mixtures. The membrane sensors were washed with water between measurements. The emf produced for each mixture was measured by the proposed electrode, and then the concentration of NFL was determined from the corresponding regression equation. 


\section{Application of pharmaceutical formulation}

Ten tablets were weighed and powdered. Two different quantities of the powdered tablets were transferred to two separate $25-\mathrm{mL}$ volumetric flask, completed to the mark with acetate buffer $(\mathrm{pH} 2.5,4 \& 4.5)$ to prepare $10^{-4}-10^{-}$ ${ }^{3} \mathrm{M}$ of NFL. The emf produced by immersing the prepared electrode in conjunction with double junction silver reference electrode in the prepared solutions was determined, and then the concentration of NFL was calculated from the regression equation of the corresponding electrode.

\section{Application to plasma samples}

$4.5 \mathrm{~mL}$ of plasma were placed into 4 Stoppard shaking tubes, and then $0.5 \mathrm{~mL}$ of $10^{-3} \mathrm{M}$ NFL were added separately and shacked. The membrane sensor was immersed in conjunction with the double junction silver reference electrode in these solutions. The membrane sensor was washed with water between measurements. The emf produced for each solution was measured by the two proposed electrodes, and then the concentration of NFL was determined from the corresponding regression equations.

\section{Results and discussion}

The stability of NFL was studied according to the ICH guidelines for:

Stress, acid and alkaline: reflux with $0.1 \mathrm{~N} \mathrm{HCl} / 0.1 \mathrm{~N} \mathrm{NaOH}$ for 8 hours, $1 \mathrm{~N}$ $\mathrm{HCl}$ for 12 hours, $2 \mathrm{~N} \mathrm{HCl}$ for 24 hours, finally $6 \mathrm{~N} \mathrm{HCl}$ for 24 hours.

Oxidative condition: reflux with $3 \% \mathrm{H}_{2} \mathrm{O}_{2}$ for 24 hours and $10 \% \mathrm{H}_{2} \mathrm{O}_{2}$ for 24 hours.

The degradation process under the previously mentioned conditions was followed using TLC and the compound was found to be stable under acidic and oxidative conditions, but it is liable to degradation in alkaline condition, giving one component which is confirmed with a previous study on stability of NFL (6). This work is concerned with the determination of NFL in presence of its alkaline degradate.

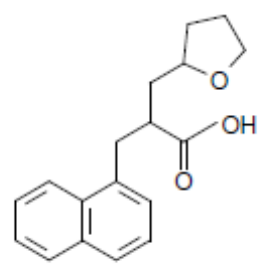

(a)

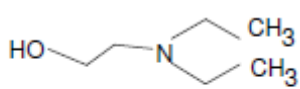

(b)

Figure 2. A suggested structure for alkaline degradation product.

To detect the complete degradation of NFL, a TLC procedure was suggested. Different systems were tried, where complete separation of NFL from its alkaline degradate was achieved using methanol-chloroform $(20: 80, \mathrm{v}, \mathrm{v})$ as the mobile phase. The $R_{f}$ values were 0.79 for NFL and 0.71 for its alkaline degradate. Using other systems such as methanol-chloroform-ammonia and butanol- 
chloroform-ammonia, butanol-ethyl acetate-ammonia, methanol-ethyl acetateammonia and methanol-ethyl acetate-acetic acid in different ratios, were not successful for separating NFL from its alkaline degradate, except methanol-ethyl acetate-ammonia in the ratio (5:5:0.1, by volume) and methanol-chloroform in the ratio $(2: 8, \mathrm{v}, \mathrm{v})$. Spotting of $5 \mu \mathrm{L}$ at different successive times of reflux and after evaporation, showed complete alkaline degradation after four hours and the obtained degradate unaffected during evaporation. It was one component in case of alkaline degradate as indicated by the appearance of one spot of alkaline degradate after complete degradation and also confirmed by IR.

A suggested structure for alkaline degradate is shown in Fig. 2 (6).

The development and application of ion selective electrode continue to be of interest for pharmaceutical analysis because this sensor offers the advantages of simple design, reasonable selectivity and fast response. The advantages of the suggested potentiometric sensors are their low cost, wide $\mathrm{pH}$ working range, wide concentration range and applicability to turbid and colored solutions (15).

The present investigation is based on the fact that NFL behaves as a cation in acidic medium, due to the presence of the amino group. This property suggests the use of anionic type of ion exchanger, sodium tetraphenyl borate with low solubility product and suitable grain size, which are functions of precipitation technique. They are physically compatible with the matrix and play the role of rapid ion exchanger for NFL at the membrane-sample interface.

In case of cyclodextrin (CD), cooperative binding with certain guest molecules has been mostly attributed to intermolecular hydrogen bonding between the CD molecules, while intermolecular interactions between both the host and guest molecules, hydrogen bonds, hydrophobic interactions and Van der Waals forces, contribute to cooperative binding processes when synthetic CDs are used.

Although the size and geometry of the guest mainly govern the binding strength, it is possible to influence the host-guest interactions by modification of the three hydroxyl groups on each glucose unit, hence the use of 2-hydroxypropyl $\beta$ cyclodextrin proved to enhance the interaction properties between host and guest molecules.

NFL forms stable 1:1 water insoluble ion association complexes. This ratio was confirmed by the elemental analysis data and by the Nernstian response of the suggested sensor which was about $60 \mathrm{mV}$, the typical value for monovalent drug (14).

PVC acts as standard support matrix and as traps for the sensed ions. It has the advantages of chemical inertness, high tensile strength and low cost, but its use makes a need for a plasticizer (16).

DOP was found to be with poor selectivity as it is non- polar, NPOE improves the results obtained by using dibutylsebathete, so it was the plasticizer of choice. The membrane constituents were dissolved in THF that was slowly evaporated at room temperature leading to the membrane formation.

Electrochemical performance characteristics of the proposed sensor were evaluated according to the IUPAC recommendation data (14), Table 1. It was found that the electrodes displayed constant and stable potential readings within 
$2 \mathrm{mV}$ from day-to-day and the calibration slopes did not change by more than 2 $\mathrm{mV}$ per decade over a period of 1 month.

Table 1. Response characteristics of the investigated electrode.

\begin{tabular}{|c|c|c|c|c|}
\hline Parameters & Sensor 1 & Sensor $2 b$ & Sensor $2 c$ & Sensor 3 \\
\hline \multicolumn{5}{|l|}{$\underline{\text { Linearity }}$} \\
\hline Slope & -57.1 & -39.7 & -40.5 & -50.5 \\
\hline Intercept & 198.6 & 213.8 & 178.3 & 215 \\
\hline $\begin{array}{l}\text { Correlation } \\
\text { coefficient }\end{array}$ & 0.9999 & 0.9997 & 0.9975 & 0.9974 \\
\hline Range & $10^{-5}-10^{-2} \mathrm{M}$ & $10^{-5}-10^{-3} \mathrm{M}$ & $10^{-5}-10^{-3} \mathrm{M}$ & $10^{-5}-10^{-3} \mathrm{M}$ \\
\hline $\begin{array}{l}\text { Response time } \\
\text { (seconds) }\end{array}$ & $20-30$ & $20-30$ & $20-30$ & $20-30$ \\
\hline $\begin{array}{l}\text { Working } \mathrm{pH} \\
\text { range }\end{array}$ & $2.60-5.50$ & $1.50-3.00$ & $2.50-5.50$ & $2.50-4.50$ \\
\hline $\begin{array}{l}\text { Life span } \\
\text { (weeks) }\end{array}$ & $6-8$ & $6-8$ & $6-8$ & $6-8$ \\
\hline Average recovery $(\%)$ & $99.97 \pm 0.408$ & $99.97 \pm 1.353$ & $99.95 \pm 1.291$ & $100.13 \pm 1.613$ \\
\hline$\%$ RSD & 0.408 & 1.353 & 1.292 & 1.612 \\
\hline
\end{tabular}

The response time of the electrode was tested for concentrations of NFL from $10^{-}$ ${ }^{6}-10^{-2} \mathrm{M}$. The measurements were characterized by a fast stable response within 20-30 seconds for concentrations less than $10^{-4} \mathrm{M}$ and 10-20 seconds for concentrations more than $10^{-4} \mathrm{M}$.

The $\mathrm{pH}$ effect was studied to be optimized from the point of view of both sensor function and chemical form of the test substance. It was apparent from the potential-pH profiles, Fig. 3-6, that the sensor responses are fairly steady over $\mathrm{pH}$ 2.6-5.5 for sensor $1, \mathrm{pH} 1.5-3.0$ for sensor $2 \mathrm{~b}, \mathrm{pH} 2.5-5.5$ for sensor $2 \mathrm{c}$ and $\mathrm{pH} 2.5-4.5$ for sensor 3 (acetate buffer). Within this range, the drug cations were completely ionized, dissociated and therefore they become sensible; above and below this $\mathrm{pH}$ range, the potentials displayed by the electrodes were noisy. The potentiometric response of the four electrodes at the optimum $\mathrm{pH}$ was linear with constant slopes over a drug concentration range $10^{-5}-10^{-2} \mathrm{M}$ for sensor 1 , and $10^{-5}-10^{-3} \mathrm{M}$ for sensors $2 \mathrm{~b}, 2 \mathrm{c}$ and 3, as shown in Fig. 7-10. 


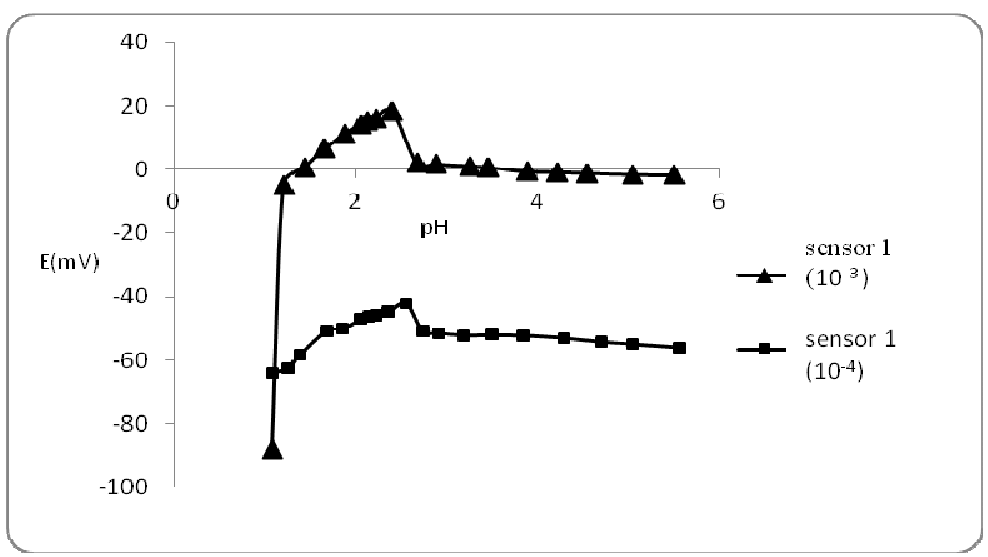

Figure 3. Effect of $\mathrm{pH}$ on the response of sensor 1.

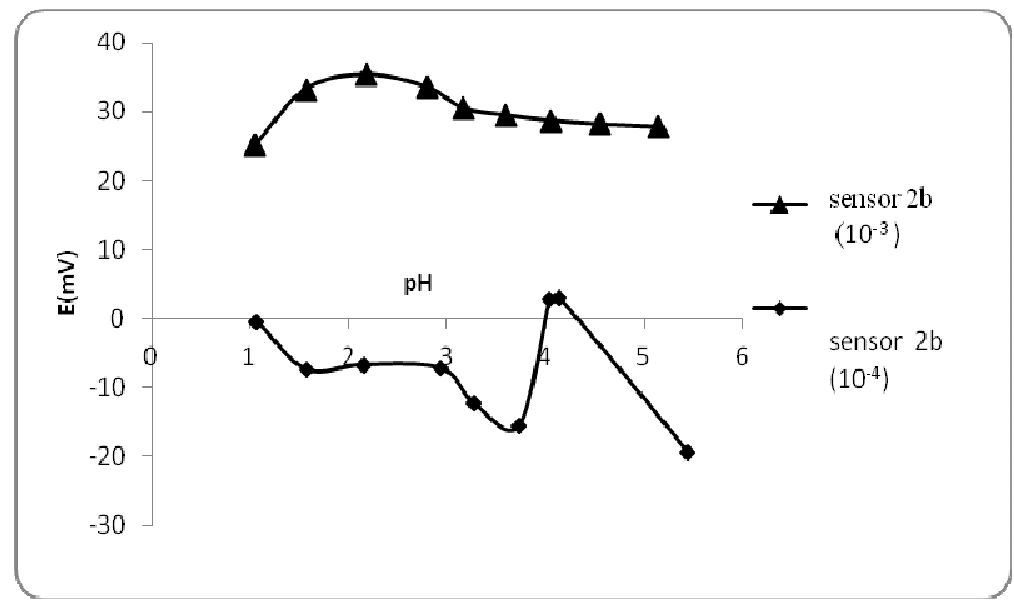

Figure 4. Effect of $\mathrm{pH}$ on the response of sensor $2 \mathrm{~b}$.

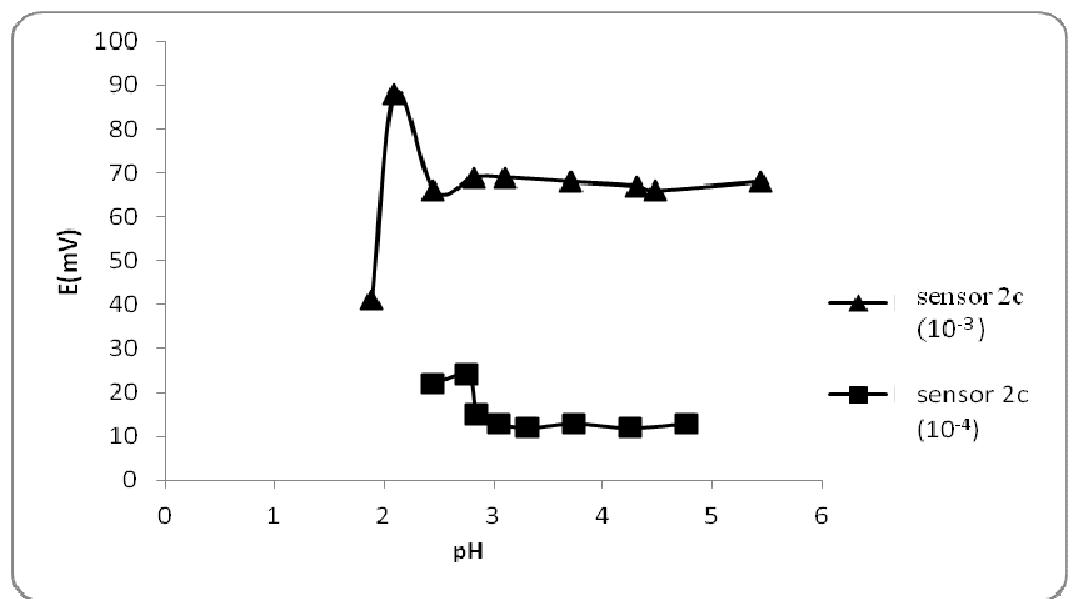

Figure 5. Effect of $\mathrm{pH}$ on the response of sensor 2c.

Table 2 shows the potentiometric selectivity coefficients of the proposed sensors in the presence of tablet excipients, degradate, organic and inorganic related substances; the results revealed that the proposed membrane sensors displayed high selectivity, and that no significant interference was observed from interfering species. Also, they revealed that sensor $2 \mathrm{~b}$ displayed greater selectivity of potential for degradate I than that of sensors $1,2 \mathrm{c}$ and 3. 
Table 2. Potentiometric selectivity coefficients of the proposed electrode using separate solution method.

\begin{tabular}{|c|c|c|c|c|}
\hline \multirow{2}{*}{ Interferent } & \multicolumn{4}{|c|}{ Selectivity coefficient } \\
& Sensor 1 & Sensor 2b & Sensor 2c & Sensor 3 \\
\cline { 2 - 5 } & $26.3 \times 10^{-3}$ & $73.3 \times 10^{-3}$ & $20.9 \times 10^{-3}$ & $9.55 \times 10^{-3}$ \\
\hline Degradation product & $4.0 \times 10^{-3}$ & $14.3 \times 10^{-3}$ & $91.8 \times 10^{-3}$ & $3.8 \times 10^{-3}$ \\
\hline $\mathrm{Na}^{+}$ & $3.7 \times 10^{-3}$ & $11.6 \times 10^{-3}$ & $108.9 \times 10^{-3}$ & $5.5 \times 10^{-3}$ \\
\hline $\mathrm{K}^{+}$ & $4.7 \times 10^{-3}$ & $9.9 \times 10^{-3}$ & $102.8 \times 10^{-3}$ & $4.8 \times 10^{-3}$ \\
\hline $\mathrm{NH}_{4}^{+}$ & $3.4 \times 10^{-3}$ & $10.3 \times 10^{-3}$ & $77.4 \times 10^{-3}$ & $6.0 \times 10^{-3}$ \\
\hline $\mathrm{Ca}^{2+}$ & $3.7 \times 10^{-3}$ & $15.5 \times 10^{-3}$ & $86.0 \times 10^{-3}$ & $4.6 \times 10^{-3}$ \\
\hline $\mathrm{Mg}^{2+}$ & $3.2 \times 10^{-3}$ & $8.1 \times 10^{-3}$ & $65.0 \times 10^{-3}$ & $5.7 \times 10^{-3}$ \\
\hline $\mathrm{Glucose}^{2}$ & $3.9 \times 10^{-3}$ & $8.7 \times 10^{-3}$ & $69.0 \times 10^{-3}$ & $5.7 \times 10^{-3}$ \\
\hline Lactose & $3.8 \times 10^{-3}$ & $10.6 \times 10^{-3}$ & $65.0 \times 10^{-3}$ & $4.8 \times 10^{-3}$ \\
\hline Starch & $3.3 \times 10^{-3}$ & $8.9 \times 10^{-3}$ & $73.1 \times 10^{-3}$ & $5.0 \times 10^{-3}$ \\
\hline Urea & $3.4 \times 10^{-3}$ & $9.8 \times 10^{-3}$ & $89.1 \times 10^{-3}$ & $5.0 \times 10^{-3}$ \\
\hline Talc & & &
\end{tabular}

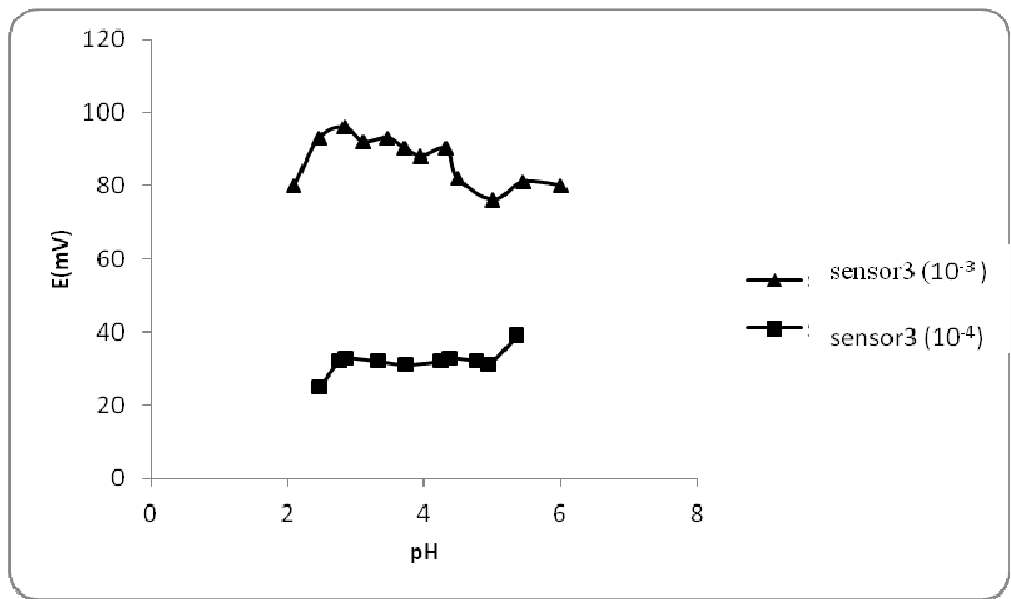

Figure 6. Effect of $\mathrm{pH}$ on the response of sensor 3.

Results of Table 3 show that the proposed method is valid and applicable for determination of NFL in different laboratory prepared mixtures with mean percentage recoveries of $100.02 \pm 0.799,102.62 \pm 2.774,99.01 \pm 1.356$ and 100.07 \pm 1.886 for NFL by sensors $1,2 \mathrm{~b}, 2 \mathrm{c}$ and 3 , respectively. The sensors can be successfully used for determination of NFL in the presence of up to $90 \%$ of degradate I, and this proved the specificity of the method.

Pharmaceutical additives, diluents and ingredients commonly used in drug formulations such as lactose, sucrose, magnesium sulphate, talc and methyl cellulose, did not show any interference. Thus, the analysis was carried out without prior treatment or extraction. The method was successfully used for the determination of NFL in praxilane tablets, as shown in Table 4.

On application to the biological fluids, it has been found that the four electrodes gave stable results, as revealed by high precision and accuracy of recoveries of 
the spiked plasma samples indicating no interference from plasma electrolytes, as shown in Table 5.

Table 3. Results of laboratory prepared mixtures of NFL in presence of its alkaline degradation product by the proposed electrodes.

\begin{tabular}{||c||c||c||c||c||}
\hline \multirow{2}{*}{$\begin{array}{c}\text { degradation } \\
\text { product } \%\end{array}$} & \multicolumn{4}{|c||}{ Ion selective electrode } \\
\cline { 2 - 5 } & Sensor 1 & Sensor 2b & Sensor 2c & Sensor 3 \\
\hline \hline $20 \%$ & 99.17 & 101.57 & 100.00 & 101.92 \\
$40 \%$ & 99.37 & 98.36 & 100.00 & 100.00 \\
$60 \%$ & 100.00 & 103.90 & 100.00 & 98.39 \\
$80 \%$ & 100.41 & 103.66 & 97.44 & 98.59 \\
$90 \%$ & 101.14 & 105.59 & 97.62 & 102.81 \\
\hline \hline & $100.02 \pm 0.799$ & $102.62 \pm 2.774$ & $99.01 \pm 1.356$ & $100.07 \pm 1.886$ \\
\hline
\end{tabular}

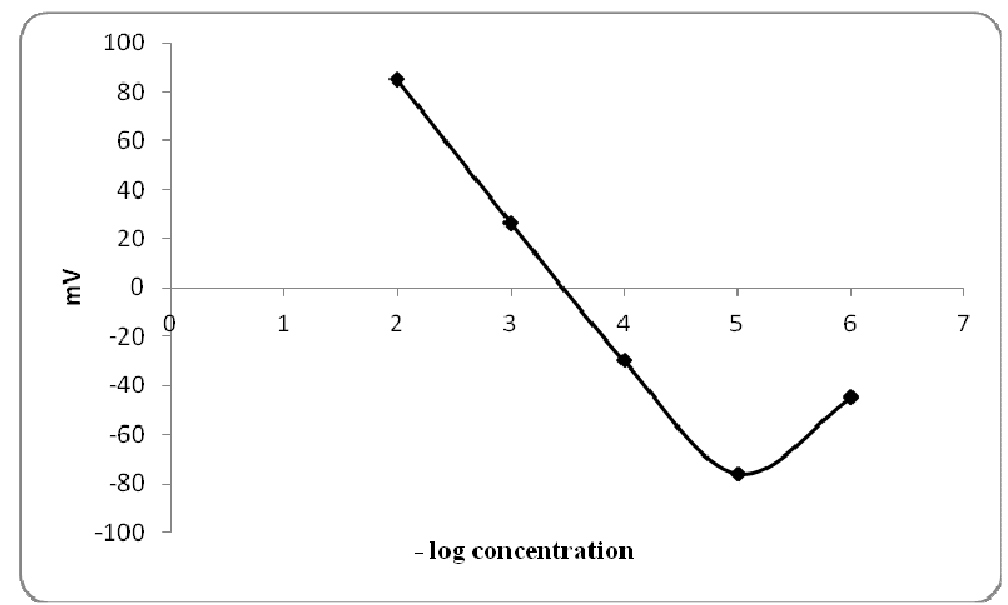

Figure 7. Profile of the potential in $\mathrm{mV}$ to the $-\log$ concentration of sensor 1 .

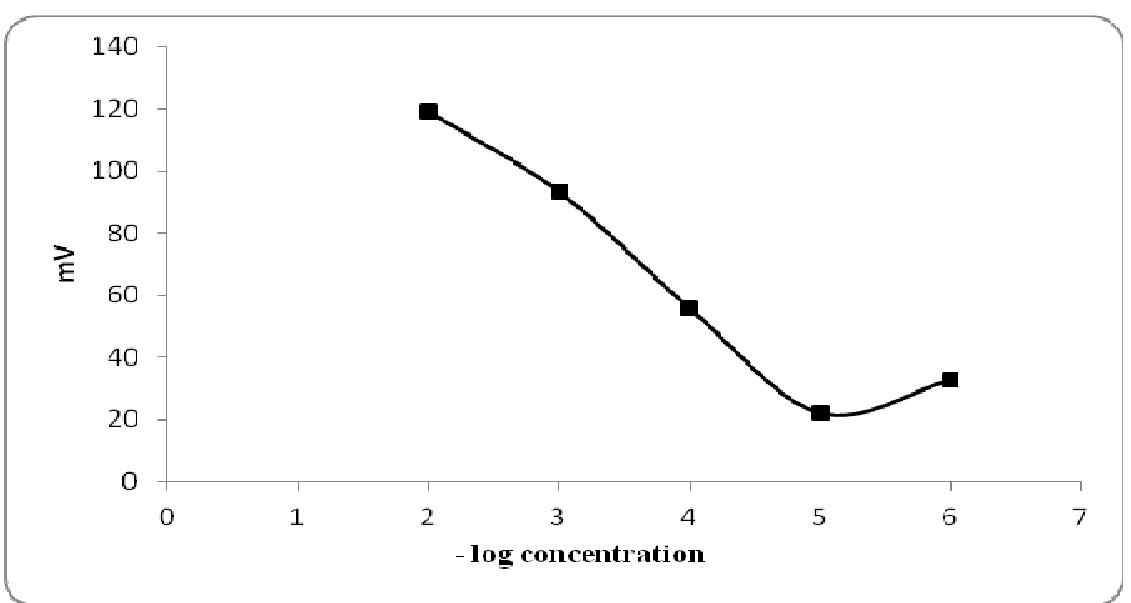

Figure 8. Profile of the potential in $\mathrm{mV}$ to the $-\log$ concentration of sensor $2 \mathrm{~b}$. 


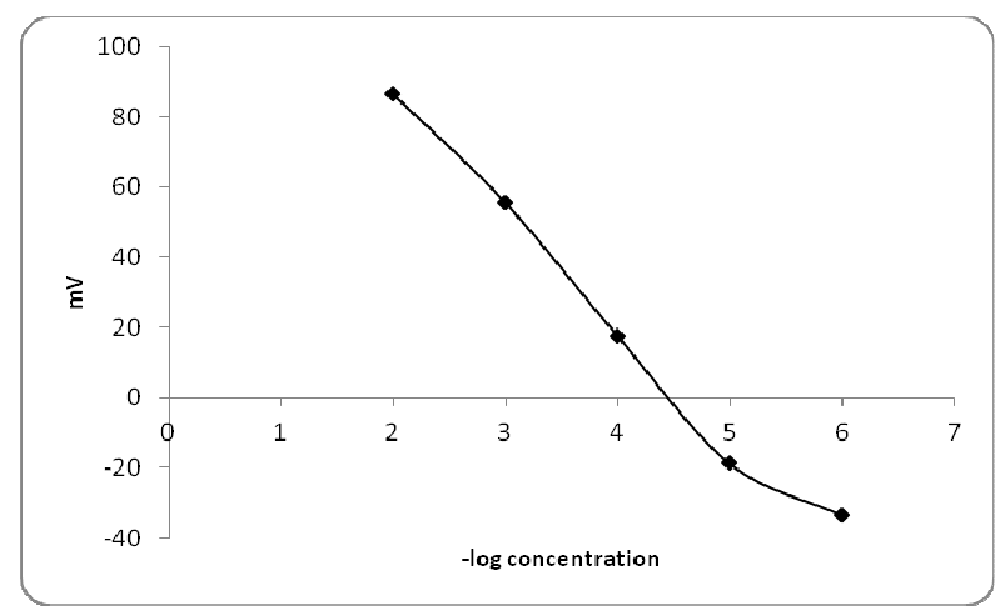

Figure 9. Profile of the potential in $\mathrm{mV}$ to the $-\log$ concentration of sensor $2 \mathrm{c}$.

The results obtained by applying the proposed methods were statistically compared with the official method (1) and no significant difference was found regarding accuracy and precision, as shown in Table 6.

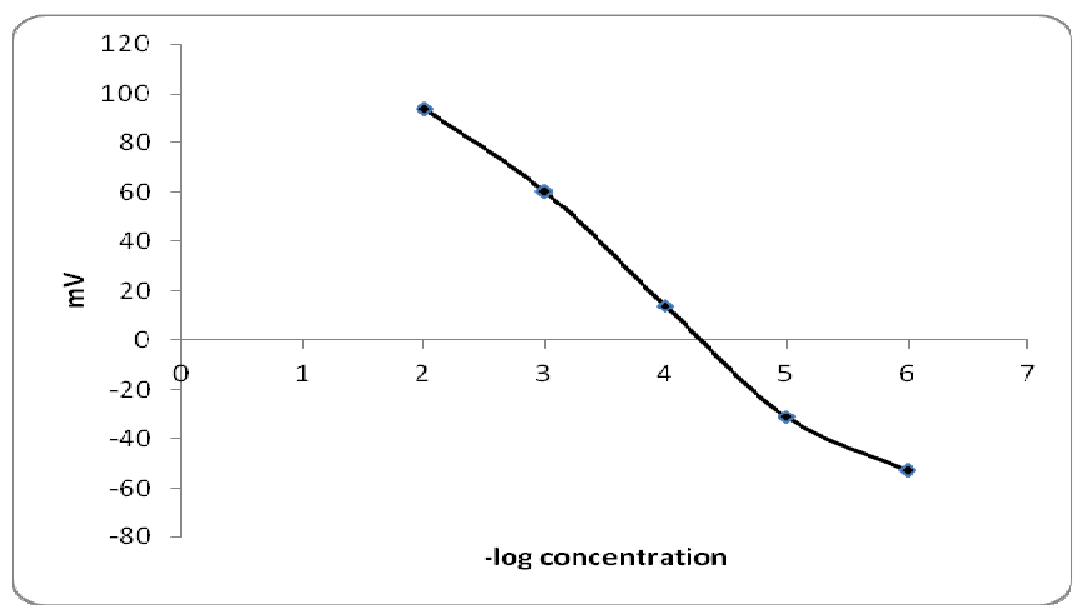

Figure 10. Profile of the potential in $\mathrm{mV}$ to the $-\log$ concentration of sensor 3 .

Table 4. Determination of NFL in Praxilane ${ }^{\circledR}$ film coated tablets by the proposed method.

\begin{tabular}{|c|c|c|c|c|c|}
\hline $\begin{array}{c}\text { Praxilane }{ }^{\circledR} \\
200 \mathrm{mg} \text { NFL/tablet }\end{array}$ & Sensor 1 & Sensor $2 b$ & Sensor 2c & Sensor 3 & Reported method \\
\hline (B.N:7HE1282) & $97.19 \pm 2.247$ & $96.01 \pm 1.284$ & $96.90 \pm 0.523$ & $97.49 \pm 0.813$ & $99.88 \pm 0.915$ \\
\hline
\end{tabular}

Table 5. Determination of NFL in spiked human plasma by the ion selective electrode.

\begin{tabular}{|c|c|c|c|c|}
\hline Concentration $(\mathrm{M})$ & Sensor 1 & Sensor $2 b$ & Sensor 2c & Sensor 3 \\
\hline $1 \times 10^{-4}$ & $96.15 \pm 0.780$ & $97.03 \pm 0.681$ & $83.33 \pm 7.217$ & $104.20 \pm 1.743$ \\
\hline
\end{tabular}


Table 6. Statistical analysis of the results of the proposed method and of the official method for determination of pure NFL.

\begin{tabular}{|c|c|c|c|c|c|}
\hline \multirow{2}{*}{ Value } & \multicolumn{4}{|c|}{ Ion selective electrode } & \multirow{2}{*}{ Reported method ${ }^{1}$} \\
\hline & Sensor 1 & Sensor 2b & Sensor 2c & Sensor 3 & \\
\hline Mean \pm SD & $100.03 \pm 0.749$ & $99.97 \pm 1.353$ & $99.95 \pm 1.291$ & $100.13 \pm 1.613$ & $100.28 \pm 1.119$ \\
\hline $\mathbf{n}$ & 4 & 3 & 3 & 3 & 6 \\
\hline Variance & 0.561 & 1.830 & 1.667 & 2.602 & 1.253 \\
\hline $\begin{array}{c}\text { Student's t } \\
\text { test } \\
(2.306)^{* *}\end{array}$ & 0.152 & 0.392 & 0.399 & 0.166 & \\
\hline F value & $2.23(9.01)^{* *}$ & $1.46(5.79)^{* *}$ & $1.33(5.79)^{* *}$ & $2.08(5.79)^{* *}$ & \\
\hline
\end{tabular}

*Non-aqueous titration with $0.1 \mathrm{M}$ perchloric acid, determining the end point potentiometrically.

** Figures in parenthesis are the corresponding theoretical values of $\mathrm{t}$ and $\mathrm{F}$ at 0.05 level of significance.

\section{References}

1. British Pharmacopoeia. London: Her Majesty's Stationary Office; 2004.

2. Brodie RR, Chasseaud LF, Taylor T, Hunter JO, Ciclitira PJ. J Chromatogr B. 1979;164:534-540.

3. Garrett ER, Barbhaiya R. J Pharm Sci. 1981;70:39-45.

4. Walmsley LM, Wilkinson PA, Brodie RR, Chasseaud LF. J Chromatogr. 1985;338:433-437.

5. Stehlik P, Houbova H. Cesk Farm. 1990;39:394-399.

6. Wang F, Dowling T, Bicker G, Wyvratt J. J Sep Sci. 2001;24:378-384.

7. Ionescu MS, Badea V, Baiulescu GE, Cosofret W. Talanta. 1986;33:101-103.

8. de la Pena M, Mansilla E, Pulgarin M, Molina A, Lopez F. Analyst. 1998;123:2285-2290.

9. Pulgarin M, Molina A, Lopez F. Anal Chim Acta. 1999;382:77-85.

10. Carretero S, Blanco C, Diaz C, Sanchez F, Gutierrez F. Anal Chim Acta. 2000;417:19-30.

11. Blanco C, Carretero S, Sanchez F, Gutierrez F. J Pharm Biomed Anal. 2000;23:845-850.

12. Li W, Cao LX, Li GR, Jin WJ. Guangpuxue Yu Guangpu Fenxi. 2002;22:518522.

13. T.S. Ma and S.S.M. Hassan, Organic Analysis Using Ion Selective Electrodes, vol. 1 and 2, Academic Press, London 1982.

14. IUPAC Analytical Chemistry Division, Commission on Analytical Nomenclature. Pure Appl Chem. 2000;72:1852.

15. Cosofret VV. Membrane electrodes in drug substances analysis. Oxford (UK): Pergamon Press; 1982.

16. Zyka J. Instrumentaion in Analytical Chemistry. Chichester (UK):Ellis Horwood; 1994. (vol 2). 